\title{
The dynamic changes of dominant clones of Staphylococcus aureus causing bloodstream infections in the European region: Results of a second structured
} survey

H Grundmann (H.Grundmann@umcg.nl)1, L M Schouls ${ }^{2}$, D M Aanensen ${ }^{3}$, G N Pluister ${ }^{2}$, A Tami ${ }^{1}$, M Chlebowicz ${ }^{1}$, C Glasner ${ }^{1}$, A J

Sabat ${ }^{1}$, K Weist ${ }^{4}, 0$ Heuer $^{4}$, A W Friedrich ${ }^{1}$, on behalf of the ESCMID Study Group on Molecular Epidemiological Markers and the European Staphylococcal Reference Laboratory Working Group ${ }^{5}$

1. Department of Medical Microbiology, University of Groningen, University Medical Center Groningen, Groningen, The Netherlands

2. National Institute for Public Health and the Environment, Bilthoven, The Netherlands

3. Department of Infectious Disease Epidemiology, Imperial College London, London, UK

4. European Centre for Disease Prevention and Control (ECDC), Stockholm, Sweden

5. Members of the group are listed at the end of the article

Citation style for this article:

Grundmann H, Schouls LM, Aanensen DM, Pluister GN, Tami A, Chlebowicz M, Glasner C, Sabat AJ, Weist K, Heuer O, Friedrich AW, on behalf of the ESCMID Study Group on Molecular Epidemiological Markers and the European Staphylococcal Reference Laboratory Working Group. The dynamic changes of dominant clones of Staphylococcus aureus causing bloodstream infections in the European region: Results of a second structured survey . Euro Surveill. 2014;19(49):pii=20987. Available online: http://www.eurosurveillance.org/ViewArticle.aspx?Articleld=20987

Staphylococcus aureus is one of the most important human pathogens and meticillin-resistant $S$. aureus (MRSA) presents a major cause of healthcare- and community-acquired infections. This study investigated the spatial and temporal changes of $S$. aureus causing bacteraemia in Europe over a five-year interval and explored the possibility of integrating pathogenbased typing data with epidemiological and clinical information at a European level. Between January 2011 and July 2011, 350 laboratories serving 453 hospitals in 25 countries collected 3,753 isolates (meticillinsensitive $S$. aureus (MSSA) and MRSA) from patients with $S$. aureus bloodstream infections. All isolates were sent to the national staphylococcal reference laboratories and characterised by quality-controlled spa typing. Data were uploaded to an interactive webbased mapping tool. A wide geographical distribution of spa types was found, with some prevalent in all European countries. MSSA was more diverse than MRSA. MRSA differed considerably between countries with major international clones expanding or receding when compared to a 2006 survey. We provide evidence that a network approach of decentralised typing and visualisation of aggregated data using an interactive mapping tool can provide important information on the dynamics of $S$. aureus populations such as early signalling of emerging strains, cross-border spread and importation by travel.

\section{Introduction}

Staphylococcus aureus is one of the major causes of bacterial infection in humans [1]. Infections occur in the community or in healthcare settings, predominantly following acquisition from mainly human sources. In
Europe, meticillin-resistant S. aureus (MRSA) are predominantly acquired in healthcare settings and represent a major challenge to the control of antibiotic resistance in hospitals. MRSA has therefore become the currency with which the success of infection control initiatives is measured at health systems level [2]. S. aureus can also acquire particular virulence traits and has been responsible for major outbreaks of toxinmediated disease in the community [3]. At the same time, $S$. aureus evolves gradually by successive acquisition of syntenic changes of largely unaltered core genomes. It is therefore possible to describe transmission and the consecutive spread of bacteria by genetic characterisation of highly polymorphic sites within the core genes of all isolates [4]. The importance of S. aureus as a human pathogen, i.e. its potential to cause large-scale outbreaks in healthcare settings and in the community, and its predominantly clonal population structure, calls for a monitoring tool that scans the distribution and spread of clones of particular public health importance over larger temporal and spatial intervals through repeated surveys. Such a tool is suited to inform public health and infection control personnel of impeding health threats.

We therefore continued with a Europe-wide initiative to explore and define any dynamic changes in the distribution and spread of clones of $S$. aureus in European hospitals five years after an initial survey was carried out in 2006 [5]. We also addressed a request from the European Centre for Disease Prevention and Control (ECDC) to explore the usefulness of integration of molecular typing data with epidemiological and clinical data at a European level. 


\section{Methods}

\section{spa typing}

Molecular typing for epidemiological purposes utilises highly discriminatory genetic markers that characterise human pathogens allowing the identification of isolates that are distinct versus those that are closely related due to recent common ancestry. The spa locus of $S$. aureus codes for Protein A, a species-specific gene product known for its IgG binding capacity. This locus is highly polymorphic due to an internal variable region of short tandem repeats which vary not only in number but also due to nucleotide substitutions within individual repeat units [6]. DNA sequences of the spa gene therefore provide portable and biologically meaningful molecular typing data that have demonstrated their utility for macro- and micro-epidemiological purposes from surveillance through to outbreak investigations at various geographical levels $[7,8]$.

\section{Capacity building}

During annually repeated workshops organised for technical personnel from European Staphylococcal Reference Laboratories (SRL), participants receive hands-on training in spa typing and data analysis according to a standard protocol using a purposedesigned software tool StaphType (Ridom GmbH, Würzburg, Germany) [8]. Proficiency testing was carried out by mailing each SRL five well-characterised $S$. aureus isolates and five sequence chromatograms (trace files) of known spa types as described previously $[9,10]$. All laboratories participating in the structured survey described here fulfilled quantifiable quality criteria which consisted of an unambiguous base-calling for all sequenced nucleotides for both forward and reverse sequencing runs of the test panel.

\section{Structured survey}

A protocol was agreed by all participating SRLs in June 2010. Using the same network of sentinel laboratories, this by and large followed the sampling frame deployed of the first structured survey carried out in 2006 [5]. Briefly, European SRLs were asked to approach sentinel hospital laboratories which already participated in the previous survey and which provide microbiological diagnostic services for a geo-demographically representative sample for their national patient population. Between January and July 2011, these laboratories were asked to submit the first five consecutive MSSA and MRSA isolates from individual patients with blood stream infection, from each hospital the laboratories served. If, due to low incidence, five MRSA isolates could not be obtained within these six months, laboratories were entitled to make up their quota of 10 isolates by submitting additional MSSA isolates. For small countries with only one laboratory, such as Cyprus and Malta, more than 10 samples were accepted within this sampling period. Isolates were dispatched by the participating laboratories to the SRLs and, whenever possible, accompanied by additional information, including sample number, date of isolation, demographic details (such as age and sex), epidemiological context (hospital-acquired if disease onset was more than 48 hours after admission, or community-onset for other cases), antibiotic resistance to isoxazolylpenicillin (i.e. oxacillin) or cefoxitin. SRLs confirmed MRSA by mecA PCR or determination of minimum inhibitory concentration for oxacillin together with PBP2a agglutination. Discrepancies between genotype or agglutination assay and susceptibility test were scored as inconclusive phenotypes. Additional information could be uploaded to the database and web application if available. This consisted of all-cause mortality 14 days after isolation of the initial bloodstream isolate. All SRLs preserved the isolates in strain collections and performed spa typing according to the standard protocol, uploaded the sequence information and made this available by synchronisation with the central Ridom SpaServer (www.spaserver.ridom.de) curated by SeqNet.org at the University Medical Center Groningen, the Netherlands $[10,11]$. Currently there are more than 13,000 spa-types and 630 repeat units stored on the SpaServer.

Epidemiological and typing data were communicated in parallel to a central purpose-designed structured query language (SQL) database at the Netherlands' National Institute for Public Health and the Environment (RIVM). For each local laboratory, SRLs also provided the postal address and decimal Cartesian coordinates for automatic geolocation. All data were anonymised and collected in accordance with the European Parliament and Council decision for the epidemiological surveillance and control of communicable disease in the European community $[12,13]$. Ethical approval and informed consent were thus not required.

\section{Data analysis and geographical illustration}

All data were inspected for inconsistencies and analysed on a country-by-country basis and returned to SRLs for feedback, clarification of inconsistencies and final approval in July 2012. After final approval, data were analysed using Stata version 11.o (College Station, Texas, USA) using Pearson chi-squared test and Fischer's exact test for proportions and Student t-test for continuous variables. Quantitative differences with the 2006 survey were reported as results. The index of diversity (ID) is an unbiased measure of the probability of drawing two different spa types given the distribution of spa types in the sample. The $95 \%$ confidence intervals (Cls) were calculated as described previously [14]. Multilocus sequence typing (MLST) sequence types were extrapolated from the spa type as per the Ridom SpaServer. Cartesian coordinates were used for geolocation and plotting on Google Maps using the geocoding facility at www.spatialepidemiology. net [15]. The web application SRL-Maps (http://www. spatialepidemiology.net/SRL-Maps2) was developed to interrogate the data based on mapping of laboratory locations. 
Geographical location of laboratories that contributed to survey of meticillin-sensitive Staphylococcus aureus and meticillinresistant S. aureus isolates, 2011

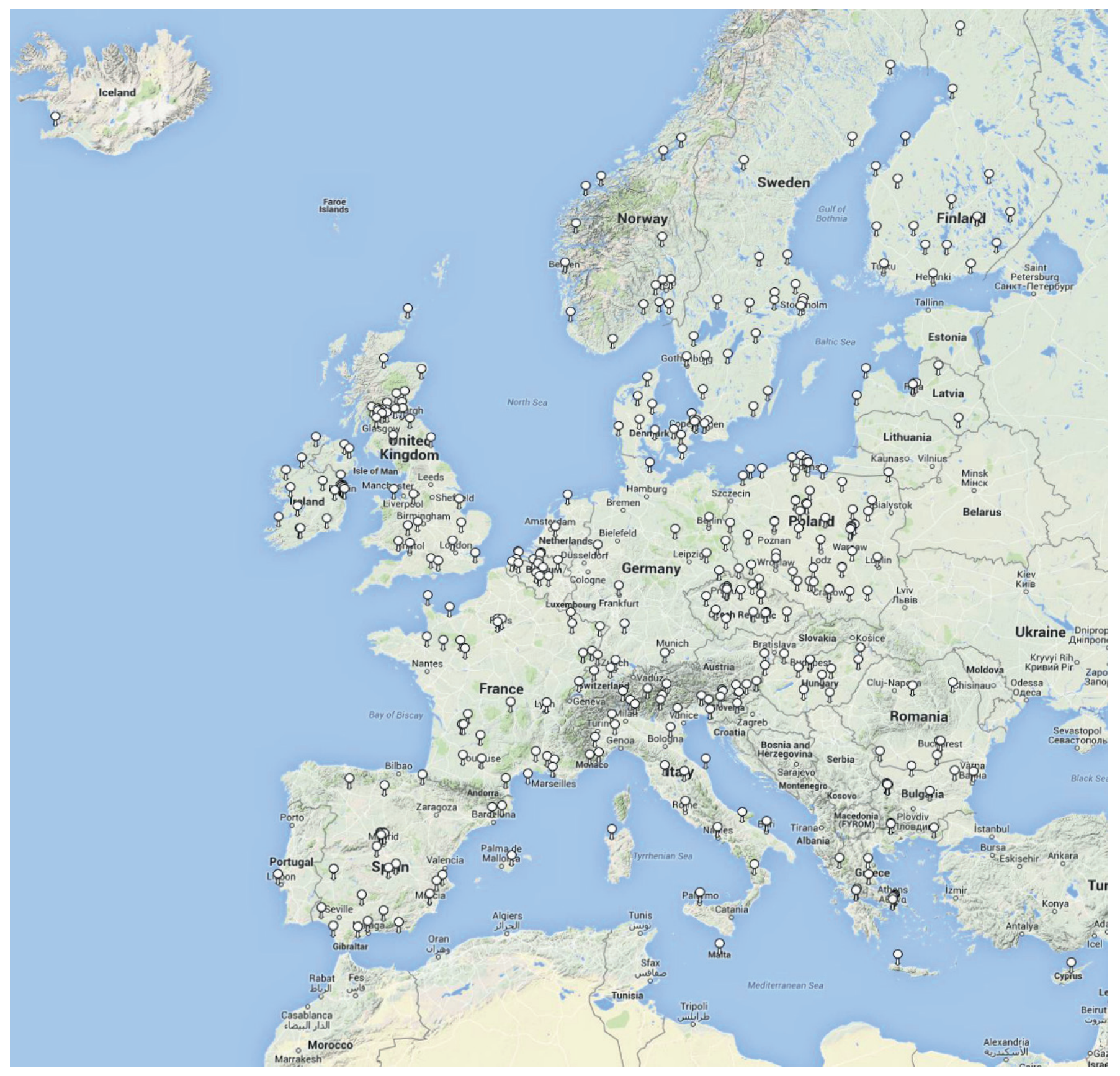

\section{Results}

\section{Summary statistics}

Between January and July 2011, laboratories from 25 European countries participated in this survey. These included 22 European Union (EU) Member States (Belgium, Bulgaria, Cyprus, Czech Republic, Denmark, Finland, France, Germany, Greece, Hungary, Ireland, Italy, Latvia, Malta, Netherlands, Poland, Portugal, Romania, Slovenia, Spain, Sweden, United Kingdom), two European Economic Area (EEA) countries (Iceland and Norway) and Switzerland. For the United Kingdom, Scotland participated on its own behalf, whereas England, Northern Ireland and Wales all referred isolates to the same reference centre in England. Two countries (Cyprus and Malta) took the deliberate decision to carry out the necessary investigations in partner (twinning) laboratories, as the sample volume would not otherwise have justified the necessary investment for sequencing equipment. Since they were also allowed to submit a larger quota, they submitted 34 and 20 isolates respectively.

Altogether, 350 laboratories (Figure 1) serving 453 hospitals submitted data for $3,753 \mathrm{~S}$. aureus isolates from patients with bloodstream infections, isolated during the six-month investigation period. Table 1 gives a summary overview of the number of participating 
Summary overview of participating laboratories, hospitals, number of invasive isolates of meticillin-sensitive Staphylococcus aureus and meticillin-resistant $S$. aureus and spa types by country, 25 European countries, 2011

\begin{tabular}{|c|c|c|c|c|c|c|c|c|c|}
\hline Country & $\begin{array}{l}\text { Number of } \\
\text { laboratories }\end{array}$ & $\begin{array}{l}\text { Number of } \\
\text { hospitals }\end{array}$ & $\begin{array}{l}\text { Number of } \\
\text { isolates }\end{array}$ & MSSA & MRSA $^{a}$ & $\begin{array}{l}\text { Number of } \\
\text { spa types } \\
\text { MSSA }\end{array}$ & $\begin{array}{l}\text { Number of } \\
\text { spa types } \\
\text { MRSA }\end{array}$ & $\begin{array}{l}\text { Number not } \\
\text { typable }\end{array}$ & $\begin{array}{l}\text { Percentage } \\
\text { non-typable }\end{array}$ \\
\hline Belgium & 17 & 17 & 133 & 76 & 57 & 53 & 25 & 3 & 2.2 \\
\hline Bulgaria & 11 & 11 & 46 & 33 & 13 & 25 & 8 & 0 & 0.0 \\
\hline Cyprus & 1 & 1 & 34 & 20 & 14 & 17 & 10 & 1 & 2.9 \\
\hline Czech Republic & 20 & 20 & 144 & 95 & 49 & 63 & 9 & 0 & 0.0 \\
\hline Denmark & 16 & 58 & 288 & 276 & 10 & 150 & 7 & 2 & 0.7 \\
\hline Finland & 17 & 43 & 173 & 163 & 10 & 89 & 5 & 2 & 1.2 \\
\hline France & 34 & 34 & 286 & 166 & 120 & 98 & 31 & 3 & 1.0 \\
\hline Germany & 10 & 26 & 161 & 100 & 61 & 62 & 22 & 0 & 0.0 \\
\hline Greece & 1 & 13 & 85 & 47 & 38 & 33 & 15 & 0 & 0 \\
\hline Hungary & 13 & 13 & 125 & 74 & 51 & 39 & 13 & 1 & 0.8 \\
\hline Iceland & 1 & 1 & 9 & 7 & 2 & 6 & 2 & 0 & 0.0 \\
\hline Ireland & 21 & 27 & 193 & 117 & 76 & 68 & 21 & 13 & 6.7 \\
\hline Italy & 23 & 23 & 200 & 103 & 97 & 61 & 36 & 0 & 0.0 \\
\hline Latvia & 8 & 8 & 36 & 33 & 3 & 17 & 2 & 1 & 2.8 \\
\hline Malta & 1 & 1 & 20 & 10 & 10 & 10 & 7 & 0 & 0 \\
\hline Netherlands & 2 & 16 & 138 & 130 & 8 & 77 & 5 & 7 & 5.1 \\
\hline Norway & 22 & n.d. & 84 & 80 & 4 & 61 & 3 & 0 & 0.0 \\
\hline Poland & 49 & 52 & 391 & 312 & 79 & 136 & 25 & 0 & 0.0 \\
\hline Portugal & 1 & 19 & 195 & 99 & 96 & 52 & 23 & 0 & 0.0 \\
\hline Romania & 5 & 5 & 37 & 15 & 22 & 13 & 7 & 0 & 0.0 \\
\hline Slovenia & 10 & 13 & 164 & 142 & 22 & 40 & 3 & 9 & 5.5 \\
\hline Spain & 1 & 30 & 129 & 35 & 94 & 30 & 27 & 0 & 0.0 \\
\hline Sweden & 23 & n.d. & 225 & 215 & 10 & 114 & 10 & 1 & 0.4 \\
\hline Switzerland & 6 & 6 & 60 & 46 & 14 & 39 & 9 & 1 & 1.7 \\
\hline $\begin{array}{l}\text { United Kingdom: } \\
\text { England, Northern } \\
\text { Ireland and Wales }\end{array}$ & 16 & 16 & 164 & 108 & 56 & 63 & 25 & 7 & $4 \cdot 3$ \\
\hline $\begin{array}{l}\text { United Kingdom: } \\
\text { Scotland }\end{array}$ & 21 & n.d. & 233 & 119 & 114 & 69 & 35 & 0 & 0.0 \\
\hline Total & 350 & 453 & 3,753 & 2,621 & 1,130 & 720 & 228 & 51 & 1.4 \\
\hline
\end{tabular}

MSSA: meticillin-sensitive Staphylococcus aureus; MRSA: meticillin-resistant S. aureus; N.d.: not determined.

a Note that the number of MRSA does not reflect a prevalence or occurrence in particular countries as the protocol asked for submission of the first five isolates of each phenotype.

laboratories and hospitals, isolates and spa types submitted by country. The combined collection consisted of $2,621(69 \%)$ MSSA and $1,130(31 \%)$ MRSA. Two isolates had an inconclusive resistance phenotype. One was spa-type t127 and the other spa non-typable.

A total of 861 different spa types were discerned, of which 720 were MSSA and 228 MRSA. Of these, $87 \mathrm{spa}$ types were shared between MSSA and MRSA. When compared with results obtained during 2006 , the spa type per isolate ratio remained at 0.23 , indicating a similar sample diversity in both surveys. There were 51 isolates (out of a total of 3,$753 ; 1.4 \%$ ) which were spa non-typable. Typability of isolates ranged from $93.3 \%$ to $100 \%$ depending on the country.
Bloodstream infections with S. aureus occurred at an older age (median 68 years, Table 2) and predominantly in men, which is in accordance with previous findings $[5,16]$. The proportion of isolates from men was higher among MRSA than MSSA bloodstream infections $(p=0.03)$. The median age at infection with MRSA was three years older than for infection with with MSSA. Compared with 2006 data, the age distribution for both MSSA and MRSA in 2011 had shifted slightly to older age groups (p<o.001).

In 2011, data on all-cause mortality 14 days after index blood culture were available for $65.5 \%$ of all cases. Overall all-cause mortality was $19.4 \%(477 / 2,458)$. There was a difference between MRSA and MSSA in 

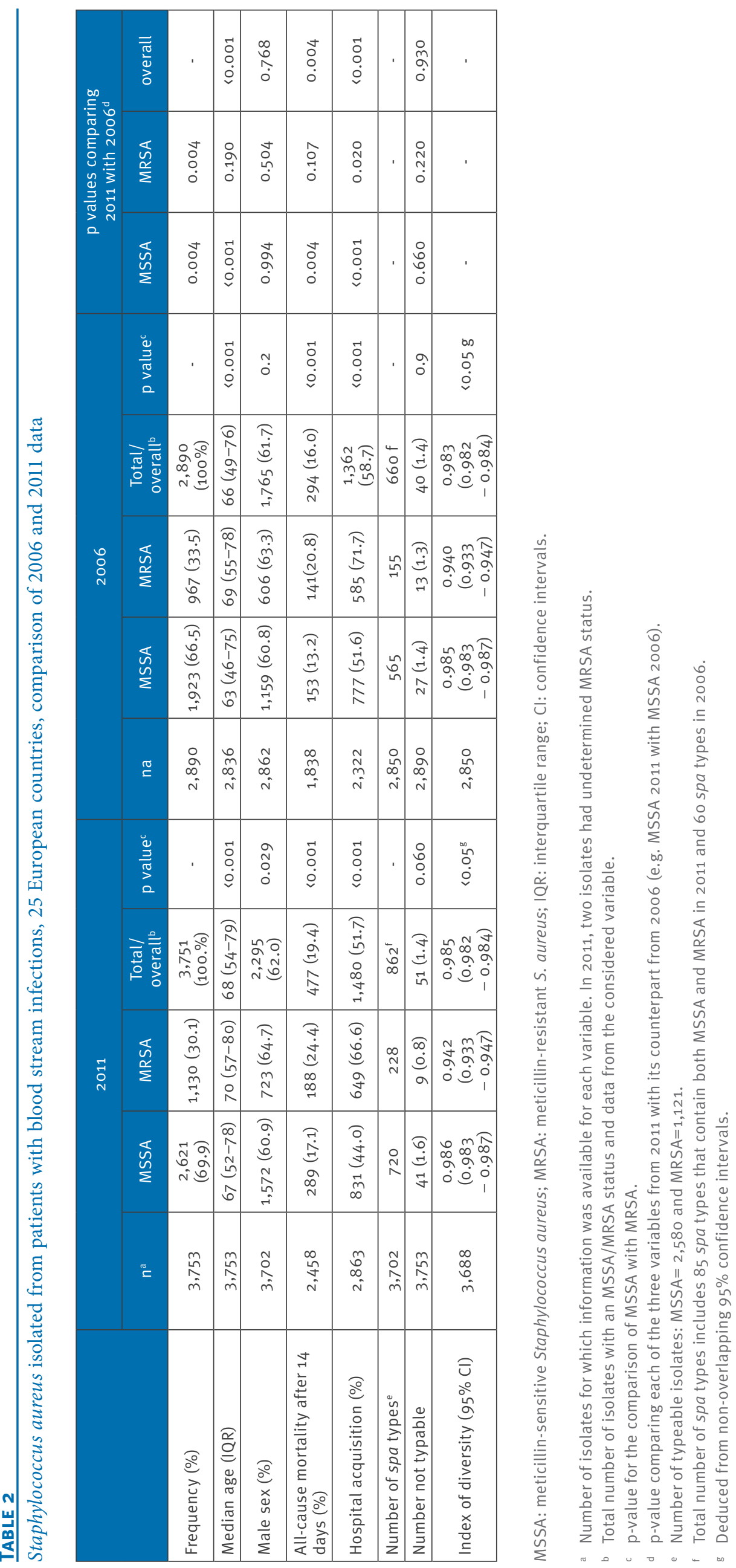
The 20 most frequent spa types and multilocus sequence typing types among meticillin-sensitive Staphylococcus aureus and meticillin-resistant S. aureus isolates collected in 25 European countries in 2011

\begin{tabular}{|c|c|c|c|c|c|c|c|c|c|c|c|}
\hline \multicolumn{6}{|c|}{ MSSA } & \multicolumn{6}{|c|}{ MRSA } \\
\hline Rank & $\begin{array}{l}\text { spa } \\
\text { type }\end{array}$ & $\begin{array}{l}\text { Multilocus } \\
\text { sequence } \\
\text { type }\end{array}$ & Frequency & $\%$ & $\begin{array}{c}\text { Cumulative } \\
\%\end{array}$ & Rank & spa type & $\begin{array}{l}\text { Multilocus } \\
\text { sequence } \\
\text { type }^{\text {a }}\end{array}$ & Frequency & $\%$ & $\underset{\%}{\text { Cumulative }}$ \\
\hline 1 & to 91 & $\mathrm{ST} 7$ & 138 & $5 \cdot 3$ & $5 \cdot 3$ & 1 & to32 & $\mathrm{ST} 22$ & 202 & 17.9 & 17.9 \\
\hline 2 & to 84 & ST15 & 124 & 4.7 & 10.0 & 2 & too3 & ST225 & 99 & 8.8 & 26.6 \\
\hline 3 & too 2 & $\mathrm{ST}_{5}$ & 121 & 4.6 & 14.6 & 3 & too 8 & ST8 & 95 & 8.4 & 35.0 \\
\hline 4 & to15 & $\mathrm{ST}_{45}$ & 98 & 3.7 & 18.4 & 4 & too2 & $\mathrm{ST}_{5}$ & 87 & 7.7 & 42.7 \\
\hline 5 & too 8 & ST8 & 97 & 3.7 & 22.1 & 5 & to67 & $\mathrm{ST} 125$ & 50 & 4.4 & 47.2 \\
\hline 6 & to12 & $\mathrm{ST}_{30}$ & 90 & 3.4 & 25.5 & 6 & to 41 & ST228 & 24 & 2.1 & 49.3 \\
\hline 7 & $\mathrm{t} 127$ & $\mathrm{ST}_{1}$ & 83 & 3.2 & 28.7 & 7 & t777 & $\mathrm{ST}_{5}$ & 21 & 1.9 & 51.2 \\
\hline 8 & to 21 & $\mathrm{ST}_{30}$ & 50 & 1.9 & 30.6 & 8 & to18 & $\mathrm{ST} 36$ & 20 & 1.8 & 52.9 \\
\hline 9 & to 65 & $\mathrm{ST}_{45}$ & 38 & 1.4 & 32.1 & 9 & to22 & $\mathrm{ST}_{22}$ & 20 & 1.8 & 54.7 \\
\hline 10 & to 26 & ST45 & 34 & 1.3 & 33.4 & 10 & to37 & ST239 & 19 & 1.7 & 56.4 \\
\hline 11 & too 5 & $\mathrm{ST} 22$ & 33 & 1.3 & 34.6 & 11 & $\mathrm{t} 127$ & $\mathrm{ST}_{1}$ & 18 & 1.6 & 58.0 \\
\hline 12 & t230 & $\mathrm{ST}_{45}$ & 32 & 1.2 & 35.9 & 12 & $\mathrm{t} 747$ & $\mathrm{ST}_{22}$ & 17 & 1.5 & 59.5 \\
\hline 13 & t216 & ST59 & 28 & 1.1 & 36.9 & 13 & to 44 & ST80 & 15 & 1.3 & 60.8 \\
\hline 14 & to56 & $\mathrm{ST} 101$ & 27 & 1.0 & 38.0 & 14 & t2357 & $\mathrm{ST}_{22}$ & 15 & 1.3 & 62.1 \\
\hline 15 & $\mathrm{t} 148$ & $\mathrm{ST} 72$ & 25 & 1.0 & 38.9 & 15 & to24 & ST8 & 14 & 1.2 & 63.4 \\
\hline 16 & to 24 & ST8 & 23 & 0.9 & 39.8 & 16 & $\mathrm{t} 740$ & ST45 & 12 & 1.1 & 64.4 \\
\hline 17 & t346 & $\mathrm{ST} 15$ & 23 & 0.9 & 40.7 & 17 & $\mathrm{t} 515$ & $\mathrm{ST} 22$ & 12 & 1.1 & 65.5 \\
\hline 18 & t571 & ST398 & 23 & 0.9 & 41.5 & 18 & t6057 & $\mathrm{ST} 22$ & 11 & 1.0 & 66.5 \\
\hline 19 & t701 & ST8 & 23 & 0.9 & 42.4 & 19 & to3o & ST239 & 9 & 0.8 & 67.3 \\
\hline 20 & t189 & ST188 & 21 & 0.8 & 43.2 & 20 & to14 & $\mathrm{ST} 225$ & 9 & 0.8 & 68.1 \\
\hline Other & - & - & 1,489 & 56.8 & 100.0 & other & - & - & 361 & 31.9 & 100.0 \\
\hline \multicolumn{3}{|l|}{ Total } & 2,621 & 100 & & \multicolumn{3}{|l|}{ Total } & 1,130 & 100 & \\
\hline
\end{tabular}

MLST: multilocus sequence typing; MSSA: meticillin-sensitive Staphylococcus aureus; MRSA: meticillin-resistant S. aureus; \%: percentage. a Predicted from spa typing data.

terms of all-cause mortality: $17.1 \%$ of patients with MSSA infections died, compared with $24.4 \%$ of patients with MRSA ( $p<0.001)$. This difference was also identified in 2006 and is explained by various confounders that put MRSA patients at a higher risk of dying than those with MSSA infections [17]. Overall, there were more patient deaths in 2011 compared with the 2006 survey $(16 \%, p=0.004)$. Although observed for both MSSA and MRSA infections, this trend was only significant for MRSA infection $(p=0.004)$. Whether this difference indicates an evolution towards more virulence or changes in host factors such as the increase in age is something that cannot be determined from this dataset.

Disease onset occurred in the community for $56 \%$ of MSSA and $33.4 \%$ of MRSA infections, indicating that MRSA remains predominantly hospital-acquired. But there was a significant increase in the proportion of cases with community onset compared with the previous survey (in 2006 48.4\% of MSSA infections had community onset, pro.001; for MRSA in the same year it was $28.3 \%, p=0.02$ ). A comparison of the most prevalent spa types among hospital-acquired MRSA (HA-MRSA) and community-onset isolates (CO-MRSA) revealed little difference (not shown). In the 2011 sample, the five top ranking spa types comprised $52 \%$ and $45 \%$ of all HA-MRSA and CO-MRSA respectively.

The high overall diversity $(I D=0.985)$ is indicative of the good discriminatory ability of spa typing but, as with the 2006 sample, there has been a significant difference between MSSA and MRSA as a result of the oligoclonal nature of MRSA spreading through European countries.

\section{Overall distribution of $s p a$ types}

For MSSA, the top 20 ranking spa types included $43.2 \%$ of all MSSA isolates (Table 3). Importantly, there was very little difference among the first 11 ranking spa types between the 2011 and 2006 datasets. Only changes in rank order were observed. Ranks 12 to 20 contained four new spa types in 2011 (Table 3). 
For MRSA, the top 20 ranking MRSA spa types contained $68.1 \%$ of all MRSA isolates (73.4\% in 2006). There were no differences in the top six spa types (albeit in relative ranking). to32/ST22 now comprises $17.9 \%$ of all MRSA sampled in 2011 (up from 14.5\% in 2006, p=0.036, Figure 2, Table 3). Except for $\mathrm{t}_{515}$, all ST22 related spa types (to32, to22, t747, t2357, t6057) have significantly increased in frequency and this lineage made up $36 \%$ of the top 20 ranking isolates in 2011, whereas in 2006 this figure was still lower at $23 \%$. Three spa types have significantly decreased compared to the 2006 collection. too8/ST8, mainly found in France, decreased from $12.4 \%$ to $8.4 \%(p=0.003)$. to $41 / \mathrm{ST}_{2} 28$ decreased from $7.4 \%$ in 2006 to $2.1 \%$ in 2011 (p<0.001). Finally, international clone to30/ST239 decreased from $2.1 \%$ to $0.8 \%(p=0.013)$.

\section{Discussion}

This survey represents a repetition of a previous study carried out in 2006 and was designed to investigate (i) the temporal and spatial changes of $S$. aureus clones of particular public health importance in Europe, and (ii) the feasibility and utility of integrating molecular typing data with epidemiological and clinical information at a European level.

We previously demonstrated the feasibility of creating a collaborative consortium of SRLs across Europe and alignment of $S$. aureus typing methodology in addition to harmonising processes and data format at European level [5]. The continuation of this effort has shown that collaboration between countries can be maintained over extended intervals and provide added value to the understanding of the dynamic spread of $S$. aureus while quality, consistency of molecular typing and communication improves.

The results described here are testimony to the usefulness of structured surveys to generate information for public health action in a timely and economic fashion. Repeating surveys through previously created networks of sentinel hospital laboratories allows for consistent observations about the changing epidemiology of infections caused by bacterial clones of particular public health importance. In case of $S$. aureus, these clones are responsible for community and hospital-acquired infections, and they are often resistant to a range of antibiotic compounds and circulate among patients of extended hospital referral networks in Europe. They typically have a defined geographical distribution and show a steady diffusion along hospital patient referral lines. Moreover, our results suggest that HA-MRSA is filtering into the community at an increasing rate. The proportion of community-onset infections caused by international HA-MRSA clones has increased over the last five years from $28.3 \%$ to $33.4 \%$. This difference is significant ( $p<0.001)$ and relevant as it indicates a trend to more export of hospital-associated clones

\section{FIGURE 2}

Comparison of meticillin-resistant Staphylococcus aureus spa-type frequencies, 2011 and 2006

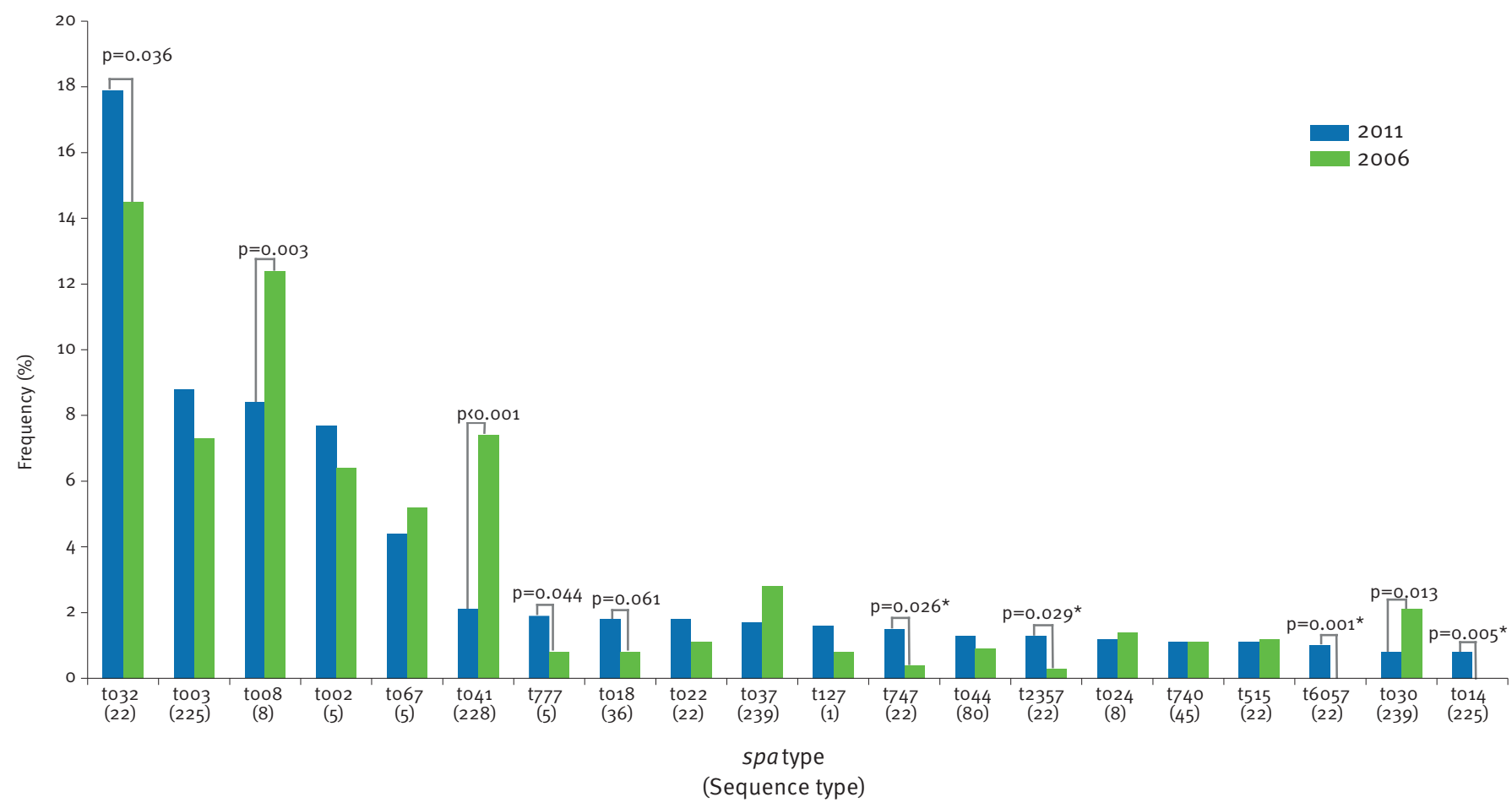

Brackets over the bars indicate the bars for which $\mathrm{p}$ values were calculated. 
into the community, probably as a result of patients' shorter hospital stays.

Among MRSA isolates, a dynamic expansion was demonstrated for several spa types. MRSA isolates with spa types belonging to ST22 increased most markedly making ST22 the most critically expanding MRSA clone in Europe. This lineage (designated EMRSA-15) was first described during hospital outbreaks in England. It caused a nationwide epidemic of healthcare-associated infections in the 1990 s and is still the most prevalent HA-MRSA in the UK [18]. This clone has spread from the UK and Ireland and has become abundant in Germany, Hungary, Portugal and Northern Italy. MRSA belonging to spa type to18/ST36 has attained a foothold in Poland and to67/ST125, abundant in Spain during the 2006 survey [19], has been causing an outbreak in hospitals in a single health district in Finland in 2011 [20]. Among MSSA, spa type t571/ST398 appears to be spreading in France and Belgium [21]. Our observations indicate that infections with this clone are more frequent among younger men and may be associated with higher mortality. Its MRSA counterpart has been described as an ancestral human variant [22] of the livestock-associated MRSA clone ST398, which caused outbreaks of community-acquired infections in northern Manhattan that were linked to immigrants from the Dominican Republic [23]. Conversely, a reduction of international clone ST239 consisting of the spa types to3o and to37 and to41/ST228 was observed. It appears that the decline of ST239 is genuine as it mainly occurred in Poland, whereas the reduction of to41/ST228 can be explained by the fact that Austria and Croatia did not participate in the 2011 survey. Both countries contributed a high proportion of this type to the 2006 dataset. This highlights the importance of consistent participation in these types of pathogenspecific surveillance initiatives and the vulnerability of networks that depend on the goodwill and enthusiasm of participants.

Limitations of this study that deserve to be addressed include a deliberate decision that was taken by the SRLs to provide only isolates from bloodstream infections. This slight deviation from the sampling frame of the previous survey may have skewed the spa type distribution slightly. Moreover, the fixed number of isolates that were collected from each participating centre was due to the trade-off between the desire to make the workload of SRLs predictable and manageable and the inability to precisely determine incidence and the absolute increase or decrease of spa types. Thus, findings generated through these types of structured surveys must be put into context of surveillance data from other European-wide initiatives such as the European Respiratory Society's (ERS-net) and/or the HealthcareAssociated Infections Surveillance Network (HAI-net). The nature of structured surveys does not allow for early warning and response as it merely provides a rather static population snapshot of the spa types, i.e. clones that were extant and caused bloodstream infections at the time of sampling. The value of these snapshots should not be underestimated, however, as they provide an unbiased view which can be used to identify clones of public health importance and their geographic abundance and can inform ad hoc epidemiological investigations about the dignity and geographical origin of organisms isolated during outbreaks.

The exchange of typing results using an illustrative mapping tool such as the spatialepidemiology.net website's SRL-maps provides the means to determine the reach and expansion of clones with proven success simultaneously for different countries. Initiatives such as these could lead to an improved and sustainable effort to control and eradicate emerging high-risk clones at the level of healthcare institutions once international agencies secure the sustainability for these repeated efforts.

A consistent integration of typing data with pre-existing epidemiological and or clinical data collected through other European surveillance initiatives (such as the European Antimicrobial Resistance Surveillance Network (EARS-net), European Surveillance of Antimicrobial Consumption Network (ESAC-net) or HAInet) will, depend on the successful implementation of further alignment of sampling methodology, diagnostic procedures and of the regulatory framework across Europe. It would require a systematic and internationally accepted identification-code for hospitals and diagnostic laboratories, as well as for bacterial isolates, which are reported through different surveillance initiatives and for patients from whom these organisms were originally recovered. This would require novel regulatory approaches on the part of European national governments. Moreover, data protection and confidentiality issues would need to be resolved before such regulations could be enacted. The alternative would be a fully decentralised approach. This would require additional efforts from hospitals and laboratories to provide pertinent epidemiological and clinical information in addition to molecular typing and antibiotic susceptibility data and to report this bundled information while maintaining full confidentiality. However, as such efforts require a considerable degree of reorganisation they may seem unrealistic under the current climate of austerity. During the deliberations with the representatives of the SRLs in our study, the possibility of collecting more accurate data about source patients (epidemiology and clinical outcome) was appraised. The prevailing consensus was that this would be unrealistic given the scarcity of information provided to diagnostic laboratories by clinicians on the request forms and the inability of laboratories to fund these additional enquiries from their own budgets. It is important to note that these concerns were not raised by single members of the SRL working group, but appear to represent a common view.

In conclusion, collaborative typing initiatives are able to identify the continental spread of high-risk clones 
across national boundaries and can indicate to healthcare providers the emergence of threats caused by successful and antibiotic-resistant bacteria. The geographic diffusion of antibiotic-susceptible and resistant clones of $S$. aureus can be made visible with the help of intuitive information tools such as interactive websites. This can improve the coherence of individual laboratory results and contribute to a better understanding of the population dynamic of these important pathogens. A simple integration of typing data with data from other existing surveillance efforts is, however, currently constrained by regulatory hurdles and legitimate concerns about patient data protection.

Members of the European Staphylococcal Reference Laboratory Working Group

Olivier Denis, Dimitr Nashev, Dominique S. Blanc, Despo Pieridou-Bagatzouni, Vladislav Jakubu, Helena Zemlickova, Henrik Westh, Anders Rhod Larsen, Robert Skov, Frederic Laurent, Franziska Layer, Wolfgang Witte, Iris Spiliopoulou, Saara Salmenlinna, Laura Lindholm, Jaana Vuopio-Varkila, Akos Toth, Erika Ungvari, Grainne Brennan, Anna Shore, Edvins Miklasevics, Arta Balode, Gunnsteinn Haraldsson, Karl G. Kristinsson, Monica Monaco, Annalisa Pantosti, Michael Borg, Xander Huijsdens, Max Heck, Lillian Marstein, Trond Jacobsen, Frode Gran, Nuno Faria, Herminia de Lencastre, Joanna Empel, Aleksandra Kozińska, Waleria Hryniewicz, Irina Codita, Maria Perez-Vazquez, Ana Vindel, Nataša Švent Kučina, Sara Haeggman, Barbro Olsson Liljequist, Bruno Pichon, Angela Kearns and Giles Edwards.

\section{Acknowledgements}

The authors would like to like to express their gratitude to all participating laboratories and hospitals throughout the European region for sharing their isolates and demographic data for the study. We would also like to thank Roel Coutinho, Director of the Center for Infection Control at RIVM for his encouragement and supporting the organisational effort of this initiative and Carola Schinkel of RIVM and Tomorrow's Events for the organisation of the annual training and planning workshops. The support and collaboration with the ESCMID Study Group of Epidemiological Markers (ESGEM) is also gratefully acknowledged.

The study was funded by ECDC through tender and framework contract ECDC 09/033.

\section{Conflict of interest}

None declared.

\section{Authors' contributions}

ICMJE criteria for authorship read and met: HG AWF. All authors agreed with the manuscript's results and conclusions. HG, AWF and the European Staphylococcal Reference Laboratory Working Group designed the experiments and the study. HG and AT analysed the data. LS, GP, MC, CG, AS and $H G$ collected data and/or did experiments for the study. $\mathrm{HG}$ wrote the first draft of the paper. $\mathrm{KW}$ and $\mathrm{OH}$ contributed to the writing of the paper. DMA developed the public domain Web-based interactive mapping tool.

References
1. Lowy FD. Staphylococcus aureus infections. N Engl J Med. 1998;339:520-32. http://dx.doi.org/10.1056/ NEJM199808203390806

2. Harbarth S, Pittet D. MRSA--a European currency of infection control. QJM. 1998;91(8):519-21. http://dx.doi.org/10.1093/ qjmed/91.8.519

3. McAdam PR, Templeton KE, Edwards GF, Holden MT, Feil EJ, Aanensen DM, et al. Molecular tracing of the emergence, adaptation, and transmission of hospital-associated methicillin-resistant Staphylococcus aureus. Proc Natl Acad Sci U S A. 2012;109(23):9107-12. Epub 2012 May 14. http://dx.doi. org/10.1073/pnas.1202869109

4. Feil EJ, Cooper JE, Grundmann H, Robinson DA, Enright MC et al. (2003) How clonal is Staphylococcus aureus? J Bacteriol. 2003;185:3307-16. http://dx.doi.org/10.1128/ JB.185.11.3307-3316.2003

5. Grundmann H, Aanensen DM, van den Wijngaard CC, Spratt BG, Harmsen D, Friedrich AW; European Staphylococcal Reference Laboratory Working Group. Geographic distribution of Staphylococcus aureus causing invasive infections in Europe: a molecular-epidemiological analysis. PLoS Med. 2010;7(1):e1000215. http://dx.doi.org/10.1371/journal. pmed.1000215

6. Frénay $H M$, Bunschoten AE, Schouls LM, van Leeuwen WJ, Vandenbroucke-Grauls CM, Verhoef J, et al. Molecular typing of methicillin-resistant Staphylococcus aureus on the basis of protein A gene polymorphism. Eur J Clin Microbiol Infect Dis. 1996; 15:60-4.

http://dx.doi.org/10.1007/BF01586186

7. Harmsen D, Claus H, Witte W, Rothgänger J, Claus H, Turnwald $\mathrm{D}$, et al. Typing of methicillin-resistant Staphylococcus aureus in a university hospital setting by using novel software for spa repeat determination and database management. J Clin Microbiol. 2003;41:5442-8. http://dx.doi.org/10.1128/ JCM.41.12.5442-5448.2003

8. Mellmann A, Friedrich AW, Rosenkötter N, Rothgänger J, Karch $H$, Reintjes R, et al. Automated DNA sequence-based early warning system for the detection of methicillin-resistant Staphylococcus aureus outbreaks. PLoS Med. 2006;3:e33. http://dx.doi.org/10.1371/journal.pmed.0030033

9. Aires-de-Sousa M, Boye K, de Lencastre H, Deplano A, Enright MC, Etienne J, et al. High interlaboratory reproducibility of DNA sequence-based typing of bacteria in a multicenter study. J Clin Microbiol. 2006;44:619-21. http://dx.doi.org/10.1128/ JCM.44.2.619-621.2006

10. Friedrich AW, Witte W, Harmsen D, de Lencastre H, Hryniewicz W, Scheres J, et al. SeqNet.org: a European laboratory network for sequence-based typing of microbial pathogens. Euro Surveill. 2006 Jan 12;11(1):E060112.4.

11. Friedrich AW, Mellman A, Harmsen D. Spa sequence typing home page. [Accessed 28 September 2009]. Available from: http://www.seqnet.org/.

12. The European Parliament and the Council of the European Union. Decision number 2119/98/EC of the European Parliament and of the Council of 24 September 1998: setting up a network for the epidemiological surveillance and control of communicable diseases in the community. Official Journal of the European Union. Luxembourg: Publications Office of the European Union. 03.10.1998: L 268. Available from: http://eurlex.europa.eu/LexUriServ/LexUriServ.do?uri=0J:L:1998:268:0 001:0006:EN:PDF

13. European Commission. Commission Decision of 22 December 1999 on the communicable diseases to be progressively covered by the Community network under Decision No 2119/98/EC of the European Parliament and of the Council (notified under document number C(1999) 4015) (2000/96 EC). EC; 2000 . Official Journal of the European Union. Available from: http://eur-lex.europa.eu/LexUriServ/LexUriServ.do?uri= CONSLEG:2000Do096:20120905:EN:PDF

14. Grundmann H, Hori S, Tanner G. Determining confidence intervals when measuring genetic diversity and the discriminatory abilities of typing methods for microorganisms. J Clin Microbiol. 2001;39:4190-2. http://dx.doi.org/10.1128/ JCM.39.11.4190-4192.2001

15. Aanensen DM, Spratt BG. Spatialepidemiology.net. Web mapping application for Infectious Disease Epidemiology. [Accessed 28 September 2009.] Available from: http://www. spatialepidemiology.net.

16. Wertheim HF, Melles DC, Vos MC, van Leeuwen W, van Belkum A, Verbrugh HA, et al. The role of nasal carriage in Staphylococcus aureus infections. Lancet Infect Dis. 2005;5(12):751-62. http://dx.doi.org/10.1016/ S1473-3099(05)70295-4

17. de Kraker ME, Wolkewitz M, Davey PG, Koller W, Berger J, Nagler J, et al. Clinical impact of antimicrobial resistance in European hospitals: excess mortality and length of hospital stay related to methicillin-resistant Staphylococcus aureus 
bloodstream infections. Antimicrob Agents Chemother.

2011;55(4):1598-605. http://dx.doi.org/10.1128/AAC.01157-10

18. Holden MT, Hsu LY, Kurt K, Weinert LA, Mather AE, Harris SR, et al. A genomic portrait of the emergence, evolution, and global spread of a methicillin-resistant Staphylococcus aureus pandemic. Genome Res. 2013;23(4):653-64. http://dx.doi. org/10.1101/gr.147710.112

19. Pérez-Vázquez M, Vindel A, Marcos C, Oteo J, Cuevas O, Trincado P, et al. Spread of invasive Spanish Staphylococcus aureus spa-type to67 associated with a high prevalence of the aminoglycoside-modifying enzyme gene ant $\left(4^{\prime}\right)$-la and the efflux pump genes $\mathrm{msrA} / \mathrm{msrB}$. J Antimicrob Chemother. 2009;63(1):21-31. http://dx.doi.org/10.1093/jac/dkn430

20. Laine I, Huttunen R, Vuento R, Arvola P, Levola R, Vuorihuhta $M$, et al. Methicillin-resistant Staphylococcus aureus epidemic restricted to one health district in Finland: a population-based descriptive study in Pirkanmaa, Finland, years 2001-2011. Scand J Infect Dis. 2013;45(1):45-53. http://dx.doi.org/10.3109/ 00365548.2012 .710853

21. Vandendriessche S, Kadlec K, Schwarz S, Denis O. Methicillinsusceptible Staphylococcus aureus ST398-t571 harbouring the macrolide-lincosamide-streptogramin B resistance gene erm(T) in Belgian hospitals. J Antimicrob Chemother. 2011;66(11):2455-9.

http://dx.doi.org/10.1093/jac/dkr348

22. Price LB, Stegger M, Hasman H, Aziz M, Larsen J, Andersen PS, et al. Staphylococcus aureus CC398: host adaptation and emergence of methicillin resistance in livestock.

MBio. 2012;3(1). pii: e00305-11. http://dx.doi.org/10.1128/ $\mathrm{mBio} .00305^{-11}$

23. Uhlemann AC, Porcella SF, Trivedi S, Sullivan SB, Hafer C, Kennedy AD, et al. Identification of a highly transmissible animal-independent Staphylococcus aureus ST398 clone with distinct genomic and cell adhesion properties. MBio. 2012;3(2) pii: e00027-12.

http://dx.doi.org/10.1128/mBio.00027-12 